(c) American Dairy Science Association, 2005.

\title{
A New Device for Measuring Kinetics of Ruminal pH and Redox Potential in Dairy Cattle
}

\author{
J. P. Marden, ${ }^{1}$ C. Bayourthe,${ }^{1}$ F. Enjalbert, ${ }^{2}$ and R. Moncoulon ${ }^{1}$ \\ ${ }^{1}$ Ecole Nationale Supérieure Agronomique, Laboratoire de Zootechnie et Qualité des Produits, \\ Avenue de l'Agrobiopole, 31326 Castanet-Tolosan, France \\ ${ }^{2}$ Ecole Nationale vétérinaire de Toulouse, Département Elevage et Produits, \\ Laboratoire d'Alimentation, Chemin des Capelles, 31076 Toulouse, France
}

\begin{abstract}
A sampling and measuring device was set up to measure continuously the $\mathrm{pH}$ and the redox potential $\left(\mathrm{E}_{h}\right)$ of ruminal content in absence of any gaseous contamination (method 1). It was compared with a conventional suction device in which no precaution was taken to prevent air from coming into contact with the surface of collected samples (method 2). Two fistulated dry cows were used and fed a total mixed ration. Redox potential and $\mathrm{pH}$ measurements were performed repeatedly on collected samples using these 2 methods during a 9 -h period; each period started $1 \mathrm{~h}$ before feeding. The partial pressure of oxygen $\left(\log f \mathrm{O}_{2}\right)$ was calculated from Nernst's equation using $\mathrm{pH}$ and $\mathrm{E}_{h}$ values. Results indicated that $\mathrm{pH}, \mathrm{E}_{h}$, and $\log f\left(\mathrm{O}_{2}\right)$ were affected by sampling method. In method $1, \mathrm{pH}$ values ranged from 6.7 to 6.37 and $\mathrm{E}_{h}$ from -173.5 to $-216.8 \mathrm{mV}$. In method 2 , $\mathrm{pH}$ and $\mathrm{E}_{h}$ values varied, respectively, from 6.93 to 6.49 and from -111.3 to $-139.5 \mathrm{mV}$. The partial pressure of oxygen was $10^{6}$ times lower in samples that were continuously collected than in hand-samples. As a result, method 1 could make accurate measurements of $\mathrm{pH}$ and $\mathrm{E}_{h}$ of ruminal content.
\end{abstract}

(Key words: redox potential, method of measurement, rumen, dairy cow)

Abbreviation key: $\mathbf{E}_{h}=$ redox potential, $\log f\left(\mathbf{O}_{2}\right)=$ partial pressure of oxygen.

\section{INTRODUCTION}

Measurements of $\mathrm{pH}$ and redox potential $\left(\mathbf{E}_{\boldsymbol{h}}\right)$ in rumen content can give a basis for the understanding of the microbiological activity and dynamics of fermentation (Broberg, 1957a). These measures were usually performed by potentiometry on rumen fluid samples collected by an oral probe or by percutaneous puncture

Received March 23, 2004.

Accepted September 28, 2004. Corresponding author: C. Bayourthe; e-mail: bayourth@ensat.fr. of the caudo-ventral ruminal sac or from a ruminally cannulated animal using a suction-strainer device (Duffield et al., 2004). In some cases, measurements were performed directly in the rumen through a well-closed rumen fistula (Broberg, 1958; Müller and Kirchner, 1969; Barry et al., 1977).

In normal conditions, the ruminal milieu is anaerobic with a redox potential markedly negative, reflecting the absence of oxygen and a strong reducing power. Nevertheless, the interpretation of $\mathrm{E}_{h}$ values reported in the literature is confusing because the redox potential is not always expressed in uniform terms. Some authors expressed $\mathrm{E}_{h}$ as a potential difference (E) between a platinum electrode and a reference electrode, i.e., calomel or silver:silver chloride. Under these conditions, " $\mathrm{E}_{h}$ " of rumen medium varied from -302 to -340 $\mathrm{mV}$ in sheep (Mathieu et al., 1996), from -335 to -370 $\mathrm{mV}$ in wether (Broudiscou et al., 2001), and from -327 to $-352 \mathrm{mV}$ in goat (Andrade et al., 2002). However, by definition, the redox potential is the potential difference between a platinum electrode and a standard hydrogen electrode (The International Hydrogen Zero). Because, in common practice, the hydrogen electrode is not used, all records must be corrected for $\mathrm{E}_{h}=\mathrm{E}_{0}+\mathrm{C}$, where $\mathrm{E}_{0}$ is the potential of the platinum electrode, and $\mathrm{C}$ is the potential of the reference electrode used relative to the standard hydrogen electrode (Kjaergaard, 1977; Sauer and Teather, 1987). After this correction, $\mathrm{E}_{h}$ values of ruminal fluid were much higher: -150 to $-260 \mathrm{mV}$ on average in sheep (Broberg, 1957b; Barry et al., 1977) and between -145 and $-190 \mathrm{mV}$ in goat (Marounek et al., 1982). Thus, the discrepancy between reported values can most likely be attributed to the fact that Mathieu et al. (1996), Broudiscou et al. (2001), and Andrade et al. (2002) did not correct the raw $\mathrm{E}_{h}$ data.

However, sampling and measuring techniques that alter the strict conditions of the ruminal milieu can also lead to sources of considerable error. The chemical composition of the ruminal liquid phase is in equilibrium with the gas mixture in the rumen headspace, composed approximately of 52 to $63 \% \mathrm{CO}_{2}, 27 \% \mathrm{CH}_{4}$, 7 to $18 \% \mathrm{~N}_{2}$, with traces of $\mathrm{H}_{2}$ and $\mathrm{H}_{2} \mathrm{~S}$ (Barry et al., 


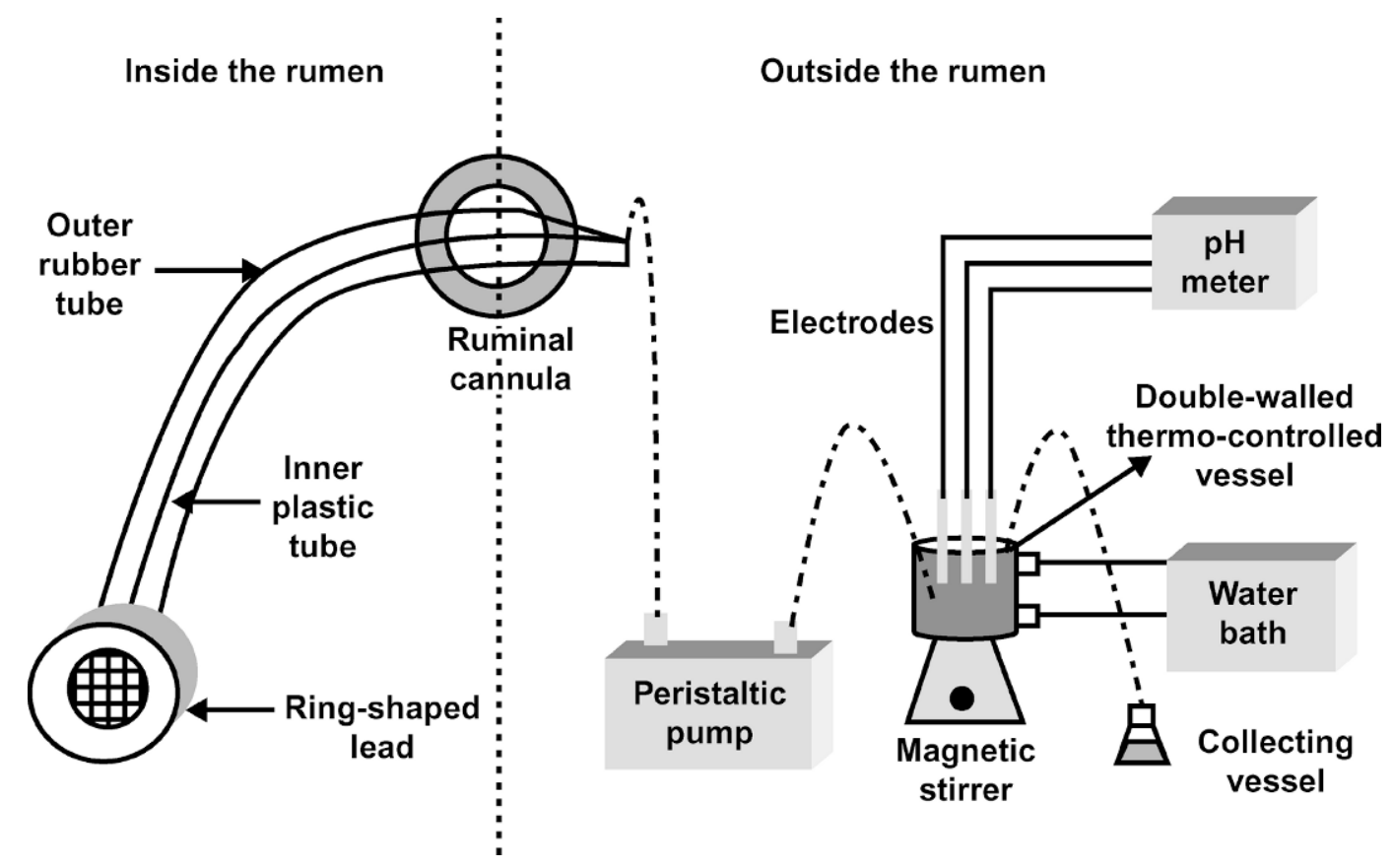

Figure 1. Method of continuous sampling and measurements with elimination of gaseous contamination.

1977; Silley, 2000). If the rumen liquor is in contact with air, $\mathrm{O}_{2}, \mathrm{CO}_{2}$, or another gaseous atmosphere different from the ruminal gas mixture, then a new equilibrium will be established that can modify the original ruminal physico-chemical characteristics (Nordstrom and Wilde, 1998).

Therefore, the aims of this work were 1) to test a new method (method 1) of measuring ruminal $\mathrm{pH}$ and $\mathrm{E}_{h}$ in absence of any oxygen contamination, by continuous pumping of ruminal fluid and 2) to compare this method to a conventional approach (method 2) which consisted of a manual suction-strainer device that pumped out ruminal fluid from a cannulated animal to measure $\mathrm{pH}$ and $\mathrm{E}_{h}$ of collected hand-samples in contact with atmospheric air.

\section{MATERIALS AND METHODS}

\section{Sampling Devices}

In method 1, the sampling device (Figure 1) was adapted from Corley et al. (1999). One part, inside the rumen, consisted of a ring-shaped lead covered on both sides with a sieve cloth of pore size $46-\mathrm{m}$, one outer rubber tube $(\mathrm{L}=650 \mathrm{~mm}$; o.d. $=18 \mathrm{~mm}$; i.d. $=6 \mathrm{~mm})$, one inner plastic tube $(\mathrm{L}=750 \mathrm{~mm}$; o.d. $=2 \mathrm{~mm}$; i.d. $=$ $1.5 \mathrm{~mm}$ ), and a perforated ruminal cannula cover. The other part, outside the rumen, was composed of a peristaltic pump (Gilson, Minipuls 2, Viliers Le Bel, France) and pumping tygon tubes (Bioblock, Illkirch, France).
The rubber tube was fused on the outside of the lead ring, and the plastic tube was connected directly to the inner part of the ring where suction of rumen fluid took place. The outer tube strengthened the small inner plastic tube during rumen contractions, and the weight of the lead ring $(1.1 \mathrm{~kg})$ maintained the filter in the middle-ventral region of the rumen. To immobilize the rubber tube outside the rumen, a perforated cannula cover of the same diameter was used. The emerging plastic tube was then connected to the peristaltic pump. Fluid that passively entered the filter was removed continuously, traveled through the plastic tube into a 50-mL double-walled thermocontrolled vessel via the peristaltic pump. The animals rapidly became accustomed to the instrument and ate, ruminated, and stayed completely undisturbed so that measurements could be taken after introduction of the device.

In method 2, ruminal fluid samples were collected at 1-h intervals from $1 \mathrm{~h}$ before feeding to $8 \mathrm{~h}$ after feeding, using a water suction pump which consisted of a polyvinyl chloride tube $(\mathrm{L}=700 \mathrm{~mm}$; o.d. $=22 \mathrm{~mm}$; i.d. $=$ $17 \mathrm{~mm}$ ), a polyvinyl chloride flask, and a vacuum pump. A composite sample of the middle-ventral region of the rumen was made. Immediately after collection, all samples were filtered through a metal sieve (1-mm mesh).

\section{Measuring Device}

The $\mathrm{pH}$ and $\mathrm{E}_{h}$ measurements were made with 3 electrodes connected to a digital $\mathrm{pH}$ meter (Metrohm 
model 713 CH-9101, Herisau, Switzerland): a glass $\mathrm{pH}$ electrode (combined electrode with diaphragm DG SC), an $\mathrm{E}_{h}$ platinum electrode ( $\mathrm{Pt} \mathrm{SC}$ with $\mathrm{Ag}: \mathrm{AgCl}$ as reference), and a platinum thermo-electrode ( $\mathrm{Pt} 100$ RNEA911 - Pt100). Electrodes were dipped in the collected rumen fluid to a depth of $4 \mathrm{~cm}$. To obtain accurate values, the measuring device in method 1 was an airtight flowthrough system. In method 2 , the collecting vessel containing hand-samples of ruminal fluid and electrodes used was in contact with air, and measurements were performed after a 25-min stabilization period as recommended by Andrade et al. (2002).

In both methods, the vessel was maintained at $39^{\circ} \mathrm{C}$ in a water bath (Exatherm U3 Electronic, Julabo, Germany). The vessel was wrapped in aluminum paper to prevent any measure fluctuations due to light intensity and placed on a magnetic stirrer (728 Stirrer, Metrohm, Switzerland) to establish equilibrium between the electrodes and ruminal fluid. After each record, the electrodes were rinsed with distilled water, dipped in $\mathrm{NaOH}$ $(1 \mathrm{~N})$, and washed again with distilled water.

\section{Experimental Procedure}

Two nonlactating Holstein cows, fitted with permanent ruminal cannulas, were used in a $2 \times 2$ Latin Square design. For each method, 2 kinetics of $\mathrm{pH}$ and $\mathrm{E}_{h}$ were established per cow and per period. The cows were fed ( $8 \mathrm{~kg}$ of DM/cow per day) with TMR offered twice daily (0900 and $1700 \mathrm{~h}$ ). The TMR consisted of $43.2 \%$ corn silage, $35.5 \%$ hay (orchardgrass and fescue), and $21.3 \%$ concentrate mixture of ground corn, soybean meal, and minerals, on a DM basis.

\section{Calculations}

Because in the actual measurements, the reference electrode was not a hydrogen electrode, all records of the potential difference were corrected using the formula:

$$
\mathbf{E}_{h}=\mathbf{E}_{\mathbf{0}}+\mathbf{C}
$$

where $\mathrm{E}_{0}$ is the potential of the platinum electrode, and $\mathrm{C}$ is the potential of the reference electrode relative to the standard hydrogen electrode (i.e., $+199 \mathrm{mV}$ at $39^{\circ} \mathrm{C}$ ) (Nordstrom, 1977).

Oxygen partial pressure, also known as oxygen fugacity $\left[\log f\left(\mathbf{O}_{2}\right)\right]$ was calculated from Nernst's equation (Valsaraj, 2000) with $\mathrm{E}_{h}$ and $\mathrm{pH}$ values:

$$
\log f\left(\mathrm{O}_{2}\right)=64.59 \mathrm{E}_{h}+4 \mathrm{pH}-78.60\left(\text { at } 39^{\circ} \mathrm{C}\right) .
$$

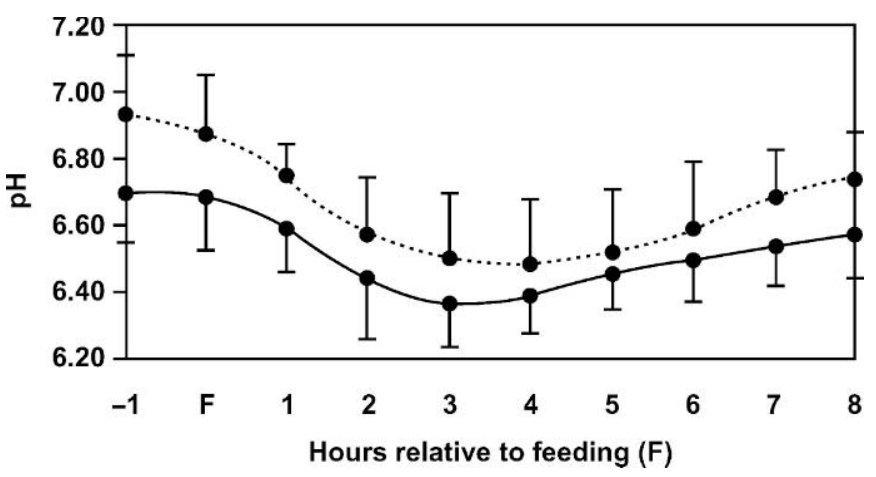

Figure 2. Dynamics of the $\mathrm{pH}$ in rumen fluid with 2 sampling methods: hand-sampling (-- ) and continuous sampling (-).

\section{Statistical Analyses}

The data were processed with the repeated measures ANOVA procedure of SYSTAT (Version 5.03 for Windows, SYSTAT Inc., Evanston, IL), which takes into account the nonindependence of the measurements between times of sampling. The statistical model was as follows:

$$
\mathrm{Y}_{\mathrm{ijk}} \text { for sampling hour } 0 \text { to } 9=\mu+\mathrm{M}_{\mathrm{i}}+\mathrm{C}_{\mathrm{j}}+\mathrm{P}_{\mathrm{k}}+\mathrm{e}_{\mathrm{ijk}}
$$

where $\mathrm{Y}$ is the dependent variable, $\mu$ is the overall mean, $M_{i}$ is the mean effect of sampling method $i, C_{j}$ is the mean effect of cow $\mathrm{j}, \mathrm{P}_{\mathrm{k}}$ is the mean effect of period $\mathrm{k}$, and $\mathrm{e}_{\mathrm{ijk}}$ is random residual. All tests were carried out with the level of significance at $5 \%$.

\section{RESULTS AND DISCUSSION}

The main objective of this study was to demonstrate how values of $\mathrm{pH}$ and $\mathrm{E}_{h}$ vary with time when exposed to air. A sampling and measuring system was set up allowing these measures to be taken without air contamination. The results (Figure 2) showed that rumen $\mathrm{pH}$ varied from 6.7 to 6.37 , and from 6.93 to 6.49 using methods 1 and 2, respectively. With both methods, rumen $\mathrm{pH}$ dropped rapidly during the first hours following feeding, reached a minimum $3 \mathrm{~h}$ after the meal, and then increased progressively. Mathieu et al. (1996) and Duffield et al. (2004) obtained similar curves. A significant difference was found between the 2 methods, and values obtained in method 2 were higher $(P=0.034)$ than in method 1 . Table 1 showed that the difference between the methods was not systematic during the entire period of measurement. Moreover, no correlation ( $R=0.08 ; n=80)$ was found to exist between the methods and consequently, no correction could be made on samples exposed to air. This difference in $\mathrm{pH}$ could be attributed to the exposure of ruminal fluid to air. As 
Table 1. Mean values and $\mathrm{pH}$ range between methods of sampling. ${ }^{1}$

\begin{tabular}{llll}
\hline & Method 1 & & Method 2 \\
\hline Mean & 6.52 & & 6.67 \\
SE & 0.11 & & 0.15 \\
Difference between initial values & & 0.23 & \\
Difference between nadir values & & 0.12 & \\
Difference between final values & & 0.17 & \\
\hline
\end{tabular}

${ }^{1}$ Method 1 = continuous pumping of ruminal fluid; method $2=$ hand-sampling.

reported by Turner and Hodgetts (1954), leaving samples in contact with air permits spontaneous losses of gases, particularly $\mathrm{CO}_{2}$, from the medium. The participation of $\mathrm{CO}_{2}$ in the fluid is determinant because when dissolved in aqueous medium, $\mathrm{CO}_{2}$ produces carbonic acid buffer $\left(\mathrm{H}_{2} \mathrm{CO}_{3}\right)$, responsible for the establishment of the correct $\mathrm{pH}$. The equation below illustrates the equilibrium between dissolved $\mathrm{CO}_{2}$ and amount of $\mathrm{H}^{+}$ ions via the production of carbonic acid.

$$
\mathrm{CO}_{2}+\mathrm{H}_{2} \mathrm{O} \leftrightarrow \mathrm{H}_{2} \mathrm{CO}_{3} \leftrightarrow \mathrm{HCO}_{3}^{-}+\mathrm{H}^{-}
$$

Variations in the amount of $\mathrm{CO}_{2}$ dissolved in an aqueous medium will automatically change the amount of $\mathrm{H}^{+}$ ions. For example, when $\mathrm{CO}_{2}$ is added, the equilibrium shifts to the right leading to the production of carbonic acid and ultimately, release of $\mathrm{H}^{+}$ions. On the other hand, when $\mathrm{CO}_{2}$ is allowed to escape, the reverse reaction occurs, i.e., production of $\mathrm{H}^{+}$ions decreases and $\mathrm{pH}$ rises. This explanation confirms that of Kohn and Dunlap (1998), who demonstrated the strong relationship between the partial pressure of $\mathrm{CO}_{2}$ and the $\mathrm{pH}$ by the Hendersen-Hasselbach equation:

$$
\mathrm{pH}_{\text {rumen }}=7.74+\log \left(\left[\mathrm{HCO}_{3}^{-}\right] / p \mathrm{CO}_{2}\right)
$$

As the ruminal $\mathrm{pH}$ is dependent upon the partial pressure of carbon dioxide, vigorous precautions must be taken to maintain the equilibrium between the ruminal gaseous mixture and the ruminal liquid phase so that correct $\mathrm{pH}$ measurements can be taken.

In the present study, method 1 provided all the necessary precautions to prevent any gaseous contamination from contacting the sample thereby maintaining the latter in its natural gaseous environment.

A highly significant difference $(P=0.001)$ was found when considering the effect of sampling and measuring techniques on rumen redox potential values. The $\mathrm{E}_{h}$ measured in rumen contents by method 1 was lower than that observed in method 2 and moved toward more reducing values over time (Figure 3). With method 1 , $\mathrm{E}_{h}$ ranged from -173.5 to $-216.8 \mathrm{mV}$. It increased $3 \mathrm{~h}$ after feeding and then slowly declined until the end

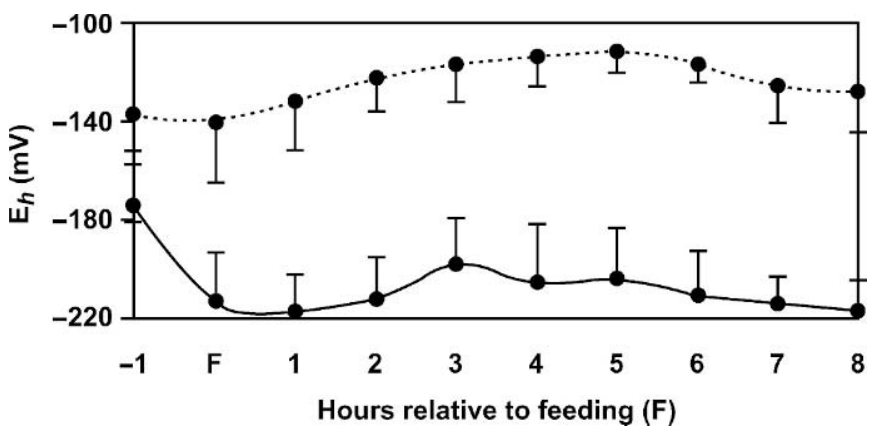

Figure 3. Dynamics of the redox potential $\left(\mathrm{E}_{h}\right)$ in rumen fluid with 2 sampling methods: hand-sampling (- - ) and continuous sampling (一).

of the measurement period. Marounek et al. (1982), Mathieu et al. (1996), and Andrade et al. (2002) obtained similar curves. The slow increase in $\mathrm{E}_{h}$ after the meal would be mainly due to the supply of oxygen directed toward the rumen during feed intake, mastication, and water intake. The subsequent decline in $\mathrm{E}_{h}$ could be explained by the rapid uptake of $\mathrm{O}_{2}$ by microorganisms (Broberg, 1957b) to maintain anaerobic conditions of the rumen. These assumptions were confirmed by Barry et al. (1977), who found higher concentrations of $\mathrm{N}_{2}$ and $\mathrm{O}_{2}$ in the gas mixture of rumen headspace during feeding than between consecutive meals.

In method $2, \mathrm{E}_{h}$ did not decrease after feeding and at no time dropped below $-140 \mathrm{mV}$. Compared with method 1, the range of $\mathrm{E}_{h}$ values was smaller, from -111.3 to $-139.5 \mathrm{mV}$. High oxidizing $\mathrm{E}_{h}$ values were observed by Broberg (1957c), who showed that bubbling air through the rumen contents resulted in an elevation of the $\mathrm{E}_{h}$, whose magnitude was directly proportional to the amount of air. The difference in $\mathrm{E}_{h}$ measurements between the methods used in our study agrees with the results of Broberg (1957b), who measured $\mathrm{E}_{h}$ in samples freely exposed to air and in samples taken and kept under $\mathrm{CO}_{2}$. It was performed to establish the effect of oxygen in air upon the $\mathrm{E}_{h}$. He showed that in presence of atmospheric oxygen, a continuous change in the $\mathrm{E}_{h}$ toward more positive values took place. On the contrary, in an atmosphere of $\mathrm{CO}_{2}$, no change in $\mathrm{E}_{h}$ could be observed and values were less than in samples exposed to air. However, as proved earlier, $\mathrm{CO}_{2}$ will modify the $\mathrm{pH}$ of the medium by shifting the equilibrium to form more $\mathrm{H}^{+}$ions. Consequently, a change in $\mathrm{E}_{h}$ would be also observed.

Therefore, we first concluded from our experiment that atmospheric oxygen was responsible for this change in $\mathrm{E}_{h}$ curve and that the absence of $\mathrm{E}_{h}$ fluctuations observed with method 2 was probably influenced by large amounts of $\mathrm{O}_{2}$, which smoothed sampling time 




Figure 4. Dynamics of the $\log f\left(\mathrm{O}_{2}\right)$ (atm) in rumen fluid with 2 sampling methods: hand-sampling (-- ) and continuous sampling $(-)$.

dependent variations as shown by the significant timemethod interaction $(P=0.0005)$. To verify the presence of oxygen, its fugacity or partial pressure was calculated [log $f\left(\mathrm{O}_{2}\right)$ ] from Nernst's equation. The results (Figure 4) showed that different $\log f\left(\mathrm{O}_{2}\right)$ curves were obtained $(P=0.0012)$ depending on whether the rumen samples were allowed to stand with the surface exposed to atmospheric air or were protected against gaseous contamination. The $\log f\left(\mathrm{O}_{2}\right)$ which resulted before feeding remained unchanged for several hours postfeeding. When rumen fluid was continuously sampled, an immediate change toward lower values was observed. During the whole measurement period, the average $\log f\left(\mathrm{O}_{2}\right)$ were $10^{-66}$ and $10^{-60}$ atm for methods 1 and 2, respectively. Thus, the lower values of $\log f\left(\mathrm{O}_{2}\right)$ obtained with method 1 showed that the environment of collecting samples remains strictly anaerobic, corresponding to the natural environment of the rumen.

\section{CONCLUSIONS}

The metabolic activity of ruminal anaerobic bacteria depends largely upon the main physico-chemical parameters, $\mathrm{pH}$ and redox potential. If these are not correctly measured using the appropriate methodology, they can be a source of considerable error. Only measures made under strict anaerobic conditions, such as those in method 1, would permit accurate diagnosis of metabolic disorders.

\section{ACKNOWLEDGMENTS}

This work was funded by a grant from Lesaffre Feed Additives. The authors gratefully acknowledge Eric Auclair.

\section{REFERENCES}

Andrade, P. V. D., S. Giger-Reverdin, and D. Sauvant. 2002. Relationship between two parameters ( $\mathrm{pH}$ and redox potential) characterising rumen status. Influence of diets. Page 332 in Proc. 9th Rencontres Recherches Ruminants, Paris, France.

Barry, T. N., A. Thompson, and D. G. Armstrong. 1977. Rumen fermentation studies on two contrasting diets. 1. Some characteristics of the in vivo fermentation, with special reference to the composition of the gas phase, oxidation/reduction state and volatile fatty acid proportions. J. Agric. Sci. Camb. 89:183-195.

Broberg, G. 1957a. Oxygen's significance for the ruminal flora as illustrated by measuring the redox potential in rumen contents. Nord. Vet. Med. 9:57-60.

Broberg, G. 1957b. Measurements of the redox potential in rumen contents. I. In vitro measurements on healthy animals. Nord. Vet. Med. 9:918-931.

Broberg, G. 1957c. Measurements of the redox potential in rumen contents. III. Investigations into the effect of oxygen on the redox potential and quantitative in vitro determinations of the capacity of rumen contents to consume oxygen. Nord. Vet. Med. 9:942-950.

Broberg, G. 1958. Measurements of redox potential in rumen contents. Nord. Vet. Med. 10:263-268.

Broudiscou, L. P., A. Agbagla-Dohnani, Y. Papon, A. Cornu, E. Grenet, and A. Broudiscou. 2001. Quantitative effects of alfalfa extract supply on rice straw degradation, fermentation and biomass synthesis by rumen micro-organisms in vitro. Anim. Res. 50:429-440.

Corley, R. N., III, M. R. Murphy, J. Lucena, and S. V. Panno. 1999. Technical note: A device for obtaining time-integrated samples of ruminal fluid. J. Anim. Sci. 77:2540-2544.

Duffield, T., J. C. Plaizier, A. Fairfield, R. Bagg, G. Vessie, P. Dick, J. Wilson, J. Aranini, and B. Mc Bride. 2004. Comparison of techniques for measurement of rumen $\mathrm{pH}$ in lactating dairy cows. J. Dairy Sci. 87:59-66.

Kjaergaard, L. 1977. Pages 131-150 in Advances in Biochemical Engineering 7. T. K. Ghose, A. Fechter, and N. Blakebrough, ed. Springer Verlag, Berlin, Germany.

Kohn, R. A., and T. F. Dunlap. 1998. Calculation of the buffering capacity of bicarbonate in the rumen and in vitro. J. Anim. Sci. 76:1702-1709.

Marounek, M., S. Bartos, and G. I. Kalachnyuk. 1982. Dynamics of the redox potential and $\mathrm{rH}$ of the rumen fluid of goats. Physiol. Bohemoslov. 31:369-374.

Mathieu, F., J. P. Jouany, J. Senaud, J. Bohatier, G. Bertin, and M. Mercier. 1996. The effect of Saccharomyces cerevisiae and Aspergillus oryzae on fermentations in the rumen of faunated and defaunated sheep; protozoal and probiotic interactions. Reprod. Nutr. Dev. 36:271-287.

Müller, R., and I. Kirchner. 1969. Determination of hydrogen-ion concentration and redox potential in the rumen content of the cattle in vitro and in vivo. 3 . Continuous measurements in vivo. Z. Tierphysiol. Tieremahr. Futtermittelkd. 25:242-247.

Nordstrom, D. K. 1977. Thermochemical redox equilibria of Zo Bell's solution. Geochim. Cosmochim. Acta 41:1835-1841.

Nordstrom, D. K., and F. D. Wilde. 1998. Reduction-oxidation potential (electrode method). Pages 3-15 in National Field Manual for the Collection of Water Quality Data. U. S. Geological Survey techniques of Water Resources Investigations, Book 9, Chapter A6, Section 6.5. US Geological Survey, Reston, VA.

Sauer, F. D., and R. M. Teather. 1987. Changes in oxidation-reduction potentials and volatile fatty acid production by rumen bacteria when methane synthesis is inhibited. J. Dairy Sci. 70:1835-1840.

Silley, P. 2000. Anaerobic microbiology - past, present and future. Don Whitley Scientific Ltd., Shipley, UK.

Turner, A. W., and V. E. Hodgetts. 1954. Buffer systems in the rumen of sheep. I. $\mathrm{pH}$ and bicarbonate concentration in relationship to pCO2. Austr. J. Agric. Res. 6:115-124.

Valsaraj, K. T. 2000. Pages 91-93 in Elements of Environmental Engineering: Thermodynamics and Kinetics. 2nd ed. Lewis Publishers, Chelsea, MI. 